\title{
Ou a vida ou o lucro: a disjuntiva neoliberal e a gestão política da morte em tempos de pandemia
}

\author{
Or the life or the profit: the neoliberal disjunctive and the political management \\ of death in pandemic times
}

\section{André Constantino Yazbek*}

Resumo: Partindo da disjuntiva neoliberal entre a vida e o lucro (ou a vida ou o lucro), o propósito deste artigo é o de discutir, no contexto da crise provocada pelo coronavírus, o conceito central de biopolítica em termos de uma gestão da morte ou, mais exatamente, de uma necropolítica.

Palavras-chave: Neoliberalismo; Crise Pandêmica; Biopolítica; Necropolítica

Abstract: Starting from the neoliberal disiunctive between life and profit (or the life or the profit), the purpose of this paper is to discuss, in the context of coronavirus crisis, the central concept of biopolitics in terms of management of death or, more exactly, necropolitics.

Keywords: Neoliberalism; Pandemic Crisis; Biopolítics; Necropolitics

"É a pavorosa peste que dizima a gente e a terra"

Sófocles, Édipo Rei

"Nada sentiria ou seria, quando muito, acometido de uma gripezinha" Jair Bolsonaro

I.

A ameaça de dissolução de nossa experiência cotidiana, ordinária e coletiva, diante de uma situação pandêmica inesperada que de súbito nos fornece o sentimento de radical gratuidade da vida - não apenas em sentido meramente biológico, mas igualmente existenciário -, guarda um potencial para promover a dissolução da naturalidade com a qual aquiescemos à ordem política e social instituída. Aliás, em seu célebre romance $A$ peste, Albert Camus já tratara de refletir sobre o duplo sentido, metafísico e político, desta espécie de experiência radical da passagem do absurdo à revolta que, com efeito, é capaz de lançarnos corajosamente no combate contra um mal do qual somos também os portadores, - "esta epidemia não me ensina nada senão que é preciso combatê-la a seu lado"1.

Diante da atual circunstância, particularmente aguda e excepcional, da conjuntura pandêmica mundial provocada pelo Sars-Cov-2 (Severe Acute Respiratory Syndrom 2), é este sentimento de radical finitude e de desnaturalização da ordem política e social que parece

${ }^{1}$ CAMUS, A Peste, p. 220.

* Professor de Filosofia na Universidade Federal Fluminense, Niterói, RJ. E-mail: andre yazbek@hotmail.com ORCID: https://orcid.org/o00o-0002-5617-6879 
emergir em seu potencial político de explicitação crítica da disjuntiva típica do neoliberalismo: ou a vida ou o lucro, - ou ainda, em termos da disjuntiva lacaniana para a definição da alienação a partir da ideia de uma perda intrínseca à "escolha forçada": ou a vida ou a bolsa $a^{2}$.

Posta nestes termos, a disjuntiva exacerbada torna-se a expressão da habitual chantagem política de um neoliberalismo também exacerbado - "nada de direitos se não houver contrapartidas" -, para o qual a aposta irresponsável na exploração ilimitada de recursos de toda sorte (naturais e humanos) vem a par com a lógica fiscalista da degradação progressiva das políticas sociais em nome de uma política de austeridade sob o pretexto da crise financeira dos Estados; crise que tornou-se já um modo de governo e que parece corroer por dentro a possibilidade mesma de uma democracia substantiva na medida em que, a pretexto da "boa governança", desativa crescentemente a margem decisória dos processos populares e esvazia a esfera reivindicatória de justiça social³.

Mas se até então parecera inexorável a manutenção da disjuntiva (ou a vida ou o lucro) e dava-se como irrealizável a possibilidade de desligamento da maquinaria capitalista que a colocara em marcha, ocorre que o advento de sua inesperada interrupção parcial (e forçada) proporcionada pela situação pandêmica atual nos fez redescobrir esta trivial verdade marxista: que a maquinaria de acumulação, com a voracidade da expansão ilimitada de sua lógica predatória, não é uma substância metafísica (a ser considerada sub specie aeternitatis), mas sim uma entidade histórica; como tal, fôra naturalizada pela mesma moderna ideologia do progresso que justificara o advento de catástrofes sociais sem precedentes no século passado, inaugurando uma forma de barbárie tipicamente moderna4. Em sentido benjaminiano, portanto, era necessário acionar o "alarme de incêndio", - "essa premonição histórica das ameaças do progresso"5. Coube ao vírus, em razão do isolamento social necessário para evitar a sobrecarga dos sistemas de saúde nacionais, esta espécie de suspensão temporária da marcha do progresso que leva à catástrofe social (e não nos esqueçamos que mesmo a pandemia atual, e as novas zoonoses emergentes, são, ao que parece, o resultado de nossa ação predatório sobre a biodiversidade ${ }^{6}$ ).

Daí que a intervenção recente de Bruno Latour, por exemplo, venha a saudar a suspensão forçada do sistema - este desligamento da máquina de um "sistema econômico que até agora nos disseram que era impossível desacelerar ou redirecionar" - como uma importante ocasião para a recusa da "produção como princípio único de relação com o mundo"7. Ora, desta perspectiva, trata-se justamente de um acontecimento histórico que implica a interrupção parcial da própria marcha predatória do progresso e, com ela, a exigência política de "invenção de um socialismo que discuta a produção em si mesma”, e

\footnotetext{
${ }^{2}$ LACAN, “Posição do Inconsciente no Congresso de Bonneval - Retomada de 1960 em 1964”, p. 326.

3 DARDOT; LAVAL, A nova razão do mundo: ensaio sobre a sociedade neoliberal, pps. 379-383.

4 "Os quatro massacres que encarnam de maneira mais acabada a modernidade da barbárie são o genocídio nazista contra os judeus e os ciganos, a bomba atômica em Hiroshima, o Goulag estalinista e a guerra norteamericana no Vietnã. Os dois primeiros são provavelmente os mais integralmente modernos: as câmaras de gás nazistas e a morte atômica norte-americana contêm praticamente todos os ingredientes da barbárie tecnoburocrata moderna”. C.f. LÖWY, Barbárie e modernidade no século XX. Disponível em: https://combate.info/barbrie-e-modernidade-no-sulo-xx/.

${ }^{5}$ LÖWY, Aviso de incêndio : uma leitura das teses "Sobre o conceito de história", p. 23.

${ }^{6}$ ROCHA, Biodiversidade é a chave para prever e evitar novas pandemias. Disponível em: http://www.abc.org.br/2020/o4/16/biodiversidade-e-chave-para-prever-e-evitar-novas-pandemias/.

7 LATOUR, Imaginar los gestos-barrera contra la vuelta a la producción anterior a la crisis. Disponível em: https://ctxt.es/es/20200401/Politica/31797/economia-coronavirus-crisis-produccion-gestos-barrera-empresasmedioambiente-bruno-latour.htm.
} 
não apenas suas injustiças distributivas ${ }^{8}$. Neste contexto, Latour evoca a ideia de um não retorno à normalidade do produtivismo capitalista, em uma espécie de apelo para a produção de gestos que possam "curto-cuircuitar" cadeias produtivas em um contexto póspandêmico, - a exemplo, justamente, da prática do "distanciamento social" naquilo que implica a possibilidade de interrupção do "trem do progresso"9.

De outra parte, e ao que me consta, no contexto brasileiro do debate atual sobre a pandemia coube a Virgínia Fontes apresentar a fórmula disjuntiva neoliberal (ou a vida ou o lucro) de maneira inequivocamente clara, posicionando-se combativamente em um textomanifesto intitulado Solidariedade social ativa e o coronavírus: a "vida antes do lucro - [a] paralisação de atividades não pode resultar em perda de salários. /.../ o vírus mostra que todos os seres humanos são iguais e que a desigualdade resulta da organização da vida social"ı. De fato, não apenas é necessária a afirmação da vida antes do lucro como, igualmente, trata-se de fazer ver que a vida, em um contexto no qual o neoliberalismo corrói a esfera pública para fins de expansão ilimitado de seu modelo - convertendo direitos sociais em mercadorias -, também já fôra "monetizada". Ora, o aspecto potencialmente disruptivo, suspensivo, da "solidariedade ativa" proposta por Fontes diz respeito ao fato de que ela implica exigências que questionam a lógica mesma do sistema neoliberal de "monetização da vida": "- dinheiro público deve ir integralmente para saúde pública! /... - a vida da população é mais importante do que os juros da dívida para milionários" ${ }^{11}$.

II.

Contudo, notemos que a disjuntiva ou a vida ou o lucro também pode ser lida como a expressão do neoliberalismo entendido em um sentido que evoca as considerações de Michel Foucault sobre a biopolítica (noção que tem sido amplamente mobilizada para refletir sobre a situação atual) e as modalidades de subjetivação constitutivas das formas deste exercício do poder. Nestes termos, o neoliberalismo deve ser compreendido em um duplo vetor: de uma parte, trata-se da forma atual da racionalidade biopolítica de gestão regular de processos biológicos vitais das populações (natalidade, fecundidade, mortalidade, epidemias, acréscimo ou decréscimo das condições de saúde, distribuição espacial populacional, etc. $)^{12}$; de outra, trata-se também da formação de certa modalidade subjetiva de obediência disciplinada correspondente à figura "empresário de si" ou "empreendedor"13, - figura por excelência da individuação obediente neoliberal. Assim, se a biopolítica, como prática de exercício de governamento - neologismo foucaultiano que indica a compreensão do poder como estruturação do campo de ação eventual de outrem ${ }^{14}$-, concerne a um

\footnotetext{
8 "Como demonstra Pierre Charbonnier, após cem anos de socialismo limitado apenas à redistribuição dos benefícios da economia, talvez seja o momento de inventar um socialismo que discuta a produção em si mesma. É que a injustiça não se limita apenas à redistribuição dos frutos do progresso, mas à própria maneira de tornar o planeta frutífero. Isso não quer dizer decrescer ou viver de amor e água fresca, mas aprender a selecionar cada segmento desse sistema supostamente irreversível, colocar em questão cada uma das conexões que se diziam indispensáveis e demonstrar, passo a passo, aquilo que é desejável e o que deixou de ser". C.f. Idem.
}

${ }^{9}$ Idem.

10 FONTES, Solidariedade social ativa e o coronavírus. Disponível em: https://apg.ufsc.br/2020/03/16/solidariedade-social-ativa-e-o-coronavirus-por-virginia-fontes/.

${ }^{11}$ Idem.

${ }_{12}^{12}$ FOUCAULT, Em defesa da sociedade: curso no Collège de France (1975-1976), p. 289-29o.

${ }^{13}$ FOUCAULT, Naissance de la biopolitque: cours au Collège de France (1978-1979), p. 236-237.

${ }^{14}$ FOUCAULT, Sobre a genealogia da ética: uma revisão do trabalho, p. 244. 
investimento capitalista sobre a vida, sua modalidade de individuação central corresponderá, por seu turno, justamente àquela do "empresário de si" na medida em que, neste modelo, "trata-se de produzir uma relação do sujeito individual com ele mesmo que seja homóloga à relação do capital com ele mesmo"15. Ora, para esta modalidade central da obediência neoliberal, cujo grau de naturalização da lógica de expansão ilimitada do capital está incorporado na forma da relação consigo, é possível, sem nenhum paradoxo, até mesmo a adoção da fórmula mistificadora segundo a qual a defesa da saúde se faz contra a economia, - fórmula que vez ou outra tem sido usada pelos porta vozes do capital e que constitui a "expressão mais direta da luta de classes em tempos de pandemia"16.

Ocorre que se a disjuntiva pôde assumir, em tempos de pandemia, a forma insidiosa da retórica empresarial de que se trata, no apelo ao isolamento social, da saúde contra a economia - e de que a economia não pode parar à custa da doença -, é porque também a morte, nesta "estatização do biológico" promovida pela biopolítica, é gerida segundo às exigências do lucro. Portanto, como já sublinhara Achille Mbembe - cuja importante contribuição tem sido a lançar uma perspectiva colonial sobre a temática da biopolítica -, a "gestão, a proteção e o cultivo da vida [são] coextensivos ao direito soberano de matar"17. Isso significa que a biopolítica contém em si os dispositivos de uma necropolítica, posto que a gestão da morte lhe é coetânea e necessária para o "governo das vidas". Trata-se aqui de uma lição que a situação pandêmica atual tende a reforçar na medida em que será explicitada, pela via do contágio e da vulnerabilidade à doença e à morte, o quanto nossas sociedades atuais, mormente as ditas periféricas, se assentam sobre a produção e a multiplicação de vidas vulneráveis ${ }^{18}$. Neste sentido, Daniele Lorenzini tem razão em afirmar, contrariando algumas das considerações de Jean-Luc Nancy ${ }^{19}$, que o "vírus não nos coloca na base da igualdade", mas sim nos revela que "nossa estrutura social depende da produção incessante da vulnerabilidade diferencial e das desigualdades sociais"20.

Assim, o que está em jogo aqui é o fato de que a biopolítica, como dispositivo de poder relativo ao "fazer viver", deve ser compreendida não exatamente como a proteção da vida tout court, mas antes como a exploração política e econômica da exposição diferencial de grupos populacionais ao risco da morte, de maneira que o "poder de causar a vida" (no

\footnotetext{
${ }^{15}$ DARDOT; LAVAL, A nova razão do mundo: ensaio sobre a sociedade neoliberal, p. 31.

16 FONTES, Coronavírus e a crise do Capital - Entrevista com Virgínia Fontes. Disponível em: https://adufs.org.br/conteudo/1883/coronavirus-e-a-crise-do-capital-entrevista-com-virginia-fontes

${ }^{17}$ MBEMBE, Necropolítica, p. 19.

${ }^{18}$ Que se tome como exemplo o mapeamento das mortes por coronavírus realizado na cidade de São Paulo pela Secretaria Municipal de Saúde no último dia 29 de abril, que mostra que a mortalidade do coronavírus é até dez vezes maior em áreas de exclusão social. O mesmo levantamento indica, ainda, que os negros moradores da cidade têm chance $62 \%$ maior de morte pelo Covid-19 do que os brancos. C.f. FIGUEIREDO, Risco de morrer por Covid-19 em SP é até 10 vezes maior em bairros com pior condição social. Portal Gı, São Paulo, 29 de abr. de 2020. Disponível em: https://g1.globo.com/sp/sao-paulo/noticia/2020/o4/29/risco-de-morrer-porcovid-19-em-sp-e-ate-10-vezes-maior-em-bairros-com-pior-condicao-social.ghtml. Lembremos ainda que a cidade de São Paulo concentra o maior número de casos do Covid-19 do Brasil e, em estudo recente do Instituto de Pesquisa Econômica Aplicada (IPEA), foi apontada como a mais desigual do país. C.f. INSTITUTO DE PESQUISAS ECONÔMICAS APLICADAS, “Desigualdades Socioespaciais de Acesso a Oportunidades nas Cidades Brasileiras - 2019”. Disponível http://www.ipea.gov.br/portal/index.php?option=com content\&view=article\&id=35268\&Itemid=444.

${ }^{19}$ Em intervenção publicada no jornal Libération, no mês de março, Jean-Luc Nancy afirmara que o "vírus nos comunisa', isto é, "nos coloca em pé de igualdade (para dizê-lo rapidamente) e nos reúne na necessidade de combate-lo em conjunto". C.f. NANCY, Communovirus. Disponível em: https://www.liberation.fr/debats/2020/03/24/communovirus 1782922.

20 LORENZINI, Biopolitics in the Time of Coronavirus. Disponível em: https://critinq.wordpress.com/2020/04/02/biopolitics-in-the-time-of-coronavirus/.
} 
sentido de incluí-la nos cálculos da seguridade capitalista) é também o "poder de devolver a morte", isto é, de multiplicar, para alguns, o risco de morte ou, pura e simplesmente, a morte política, a expulsão, o exílio, etc ${ }^{21}$. Ou a vida ou o lucro significa, neste sentido, que a condição que torna "aceitável" este manejo da exposição diferencial de setores da população ao risco da morte, ou mesmo ao risco social, depende da formação politicamente orientada de contingentes crescentes de grupos de indesejáveis que, marcados com os estigmas interseccionais de raça, classe e gênero, terão suas vidas regularmente (e "justificadamente") sacrificadas ao lucro. E é por este motivo que Foucault estabelecerá o racismo como o campo de articulação da co-extensividade do moderno governo gestionário da vida com o arcaico direito soberano de decretar a morte: haja vista que a biopolítica, sem que isso represente nenhuma contradição, necessita crescentemente da mobilização da violência estatal massiva, ordenada de modo sistemático, a prerrogativa tipicamente soberana do poder aquela de requerer a morte de seus súditos - é redistribuída segundo a lógica de um racismo constitutivo dos estados modernos ${ }^{22}$. Portanto, a tarefa mesma do moderno governo biopolítico da vida, na medida em que não denega as funções assassinas do Estado, implica em reinscrever incessantemente o racismo no político para justificar e tornar aceitável a execução de um direito (de soberania) e uma prática (de biopoder) que marcam seu domínio sobre vida por meio de seu exaurimento. Em uma palavra: trata-se da produção gestionária da morte no interior mesmo de espaços políticos formalmente balizados pelos direitos do homem e da humanidade.

\section{III.}

Mas notemos ainda a singularidade dos países ditos periféricos: ora, se a formação de grupos de indesejáveis, populações passíveis de terem suas vidas expostas à morte, é um elemento imanente à lógica biopolítica dos estados liberais em geral, em países como o Brasil - cuja matriz histórica é a da violência colonial entendida como "primeira síntese entre massacre e burocracia" 23 -, a disjuntiva neoliberal (ou a vida ou o lucro) apresenta-se em sua forma ainda mais dramática, posto que reatualiza a inominável infâmia de nossa tradição escravocrata, adequando sua violência às exigências do contemporâneo neoliberalismo ("a versão mais antisocial do capitalismo", como a definiu Boaventura Santos) ${ }^{24}$. Assim, pode-se falar, entre nós, de uma autêntica necropolítica - compreendida como a distribuição massiva da morte para tornar possíveis as funções tanato-gerenciais do Estado brasileiro -, sem os "anteparos" de qualquer veleidade prática de formação de um contrato-social que fosse capaz de promover a integração efetiva dos mínimo-assalariados

\footnotetext{
${ }^{21}$ FOUCAULT, Em defesa da sociedade: curso no Collège de France (1975-1976), p. 306.

22 "Com efeito, que é o racismo? É, primeiro, o meio de introduzir afinal, nesse domínio da vida de que o poder se incumbiu, um corte: o corte entre o que deve viver e o que deve morrer". C.f. Idem, p. 304

${ }^{23}$ MBEMBE, Necropolítica, p. 32.

24 "Ora, foi isto o que aconteceu nos últimos quarenta anos, sobretudo depois da queda do Muro de Berlim. Impôs-se a versão mais anti-social do capitalismo: o neoliberalismo crescentemente dominado pelo capital financeiro global. Esta versão do capitalismo sujeitou todas as áreas sociais - sobretudo saúde, educação e segurança social- ao modelo de negócio do capital, ou seja, a áreas de investimento privado que devem ser geridas de modo a gerar o máximo lucro para os investidores. Este modelo põe de lado qualquer lógica de serviço público, e com isso ignora os princípios de cidadania e os direitos humanos. Deixa para o Estado apenas as áreas residuais ou para clientelas pouco solventes (muitas vezes, a maioria da população) as áreas que não geram lucro. Por opção ideológica, seguiu-se a demonização dos serviços públicos (o Estado predador, ineficiente ou corrupto); a degradação das políticas sociais ditada pelas políticas de austeridade sob o pretexto da crise financeira do Estado; a privatização dos serviços públicos e o subfinanciamento dos que restaram por não interessarem ao capital”. C.f. SANTOS, A cruel pedagogia do vírus, p. 24.
} 
no espaço público. Daí que o Welfare State, entre nós, não tenha passado de um sonho de uma noite de verão - para fazer uso do clichê shakespeariano -, um momento episódico, logo ceifado pelo reestabelecimento da lógica da violência colonial e de sua caraterística indistinção (para largos setores populacionais) entre as "zonas de guerra" e as "zonas de paz"25.

No momento em que escrevo estas linhas, a situação da pandemia no Brasil começa a atingir uma escala dramática: dados do próprio Ministério da Saúde, divulgados em vinte e nove de abril de 2020, apontam para 5.466 mortes e 78.162 caso confirmados, - e a tendência parece ser a da continuidade de um aumento exponencial ${ }^{26}$. Mas a expressão de maior teor simbólico de nossa tragédia são as valas comuns que se multiplicam pela cidade de Manaus, capital do Amazonas, cuja média de enterros chegou a 100 por dia e, evidentemente, colapsou o sistema funerário. Como uma espécie de realização explicita das operações materiais de uma necropolítica que nega até mesmo o corpo morto das populações periféricas e dos povos originários - não reconhecendo um genocídio que se prolonga até os dias atuais -, há notícias de cadáveres que continuam em suas residências à espera do serviço funerário, colapsado pelo ritmo das mortes; e algumas famílias abrem caixões lacrados à beira das covas coletivas para confirmarem a identidade dos familiares a serem sepultados, - sob o olhar complacente de coveiros que partilham a mesma dor e, possivelmente, a mesma origem social ${ }^{27}$. Tais cidadãos não estão "apenas" privados de velarem por seus mortos - uma privação que a pandemia impôs a muitos outros - mas estão, isto sim, assistindo a uma segunda morte: a dos corpos que não obtém descanso nem mesmo quando cadáveres. Neste sentido, eles são a representação dos discriminados entre os discriminados, dos desprovidos de todo o tipo de reconhecimento, assemelhando-se, por isso mesmo, aos não-enlutáveis dos quais nos fala Judith Butler: a "desigualdade social e econômica assegurará que o vírus discrimine"28.

Chegado a este ponto, em que a pandemia atinge sua curva trágica, resta lembrarmos que o Brasil de abril de 2020 , no contexto mesmo de sua crise sanitária, é um país igualmente assolado pelo acirramento de uma crise democrática enormemente aprofundada por um governo federal de coloração francamente autoritária, e mesmo proto-fascista. Negacionista de primeira hora, integrante do "clube" dos quatro chefes de Estado que relutam em admitir a gravidade da situação pandêmica e mesmo a existência do vírus composto pelos governantes da Bielorússia, do Turcomenistão e da Nicarágua -, paranoico conspiracionista, o senhor Jair Bolsonaro tornou-se o elemento desencadeador daquilo que Paul Virilio, tratando de definir o fascismo, chamou de um Estado Suicidário, e que Deleuze e Guattari, comentando a própria definição de Virilio, dirão tratar-se de "uma máquina de guerra que não tinha mais objetivo a não ser a guerra, e que aceitava abolir seus próprios

\footnotetext{
${ }^{25}$ Nas palavras de Mbembe, “o direito soberano de matar não está sujeito a qualquer regra nas colônias. Lá, o soberano pode matar em qualquer momento ou de qualquer maneira. /.../ A paz não constitui necessariamente a consequência natural de uma guerra colonial. De fato, a distinção entre guerra e paz não é pertinente”. C.f. MBEMBE, Necropolítica, p. 36-37.

26 BRASIL tem 5.466 mortes e 78.162 casos confirmados por coronavírus. Disponível em: https:/g1.globo.com/bemestar/coronavirus/noticia/2020/o4/29/brasil-tem-5466-mortes-porcoronavirus.ghtml.

${ }_{27}$ BOECHAT, Famílias abrem caixões lacrados à beira das covas coletivas para ter certeza de que estão enterrando seus parentes em Manaus. Disponível em: https://br.noticias.yahoo.com/familias-abrem-caixoes-abeira-das-covas-coletivas-para-ter-certeza-de-que-estao-enterrando-seus-parentes-em-manaus$161006292 . \mathrm{html}$.

28 BUTLER, El capitalismo tiene sus limites, p. 62. Disponível em: http://tiempodecrisis.org/wpcontent/uploads/2020/o3/Sopa-de-Wuhan-ASPO.pdf?fbclid=IwAR386959-

q7FG9ZCeGsEFSxGBOerZNNMf3sihmLn8nYjcieT4QA-yyx6zE
} 
correligionários antes do que deter a destruição", um processo cujo mecanismo, uma vez posto em marcha, "não pode desembocar na paz, pois a estratégia indireta instala efetivamente o poder dominante fora das categorias usuais do espaço e do tempo" 29 . A disjuntiva ou a vida ou o lucro torna-se, aqui, a expressão irretocável de uma tanatopolítica que se reivindica da herança dos porões dos torturadores de nossa ditadura civil-militar, motivo pelo qual, nas palavras de Vladimir Safatle, trata-se de "fazer desaparecer corpos"зo.

Resta saber se essa tanatopolítica à brasileira, por conta do grau de stress e esgotamento a que serão submetidos os aparatos hospitalares e ambulatoriais públicos, e diante da impossibilidade de assegurar suficiente assistência médico-populacional em uma situação limite de vida e morte - que atingirá não apenas os infectados pelo covid-19 mas todos os que necessitam de cuidados médicos em situação de doença grave ou emergência fatal -, explicitará em graus intoleráveis os processos de violência gestionária estatal em sua produção política de vidas que valem a vida e vidas que valem a morte. Neste caso, tornar-seá patente e generalizado - inclusive para as classes que possuem seguro saúde e condições para manter-se em isolamento social - o fato de que matar ou morrer são, em um regime como o nosso, a forma mesma da implantação e da manifestação política do poder estatal (agora estendidas a outras porções populacionais).

\section{Referências}

ANTUNES, R. O Privilégio da Servidão: o novo proletariado de serviços na era digital. São Paulo: Boitempo, 2018.

BRASIL tem 5.466 mortes e 78.162 casos confirmados por coronavírus. Portal G1, 30 de abr. de 2020. Disponível em: https://g1.globo.com/bemestar/coronavirus/noticia/2020/04/29/brasil-tem-5466-mortespor-coronavirus.ghtml. Acesso em: 30/04/04.

BOECHAT, Y. Famílias abrem caixões lacrados à beira das covas coletivas para ter certeza de que estão enterrando seus parentes em Manaus. Yahoo Notícias, 29 de abr. de 2020. Disponível em: https://br.noticias.yahoo.com/familias-abrem-caixoes-a-beira-das-covascoletivas-para-ter-certeza-de-que-estao-enterrando-seus-parentes-em-manaus161006292.html. Acesso em: 29/04/2020.

BUTLER, J. El capitalismo tiene sus limites. In: Sopa de Wuhan. Ed. ASPO (Aislamiento Social Preventivo y Obligatorio). Disponível em: http://tiempodecrisis.org/wpcontent/uploads/2020/o3/Sopa-de-Wuhan-ASPO.pdf?fbclid=IwAR386959q7FG9ZCeGsEFSxGBOerZNNMf3sihmLn8nYjcieT4QA-yyx6zE. Acesso em o4/o4/2020.

CAMUS, A. A Peste. Trad. de Valerie Rumjanek. Rio de Janeiro: Record, 2013.

DELEUZE, G.; GUATTARI, F. Mille plateaux. Paris: Minuit, 1980.

BENJAMIN, W. Sens unique. Paris: Lettres nouvelles/Maurice Nadeau, 1978.

FIGUEIREDO, Patrícia. Risco de morrer por Covid-19 em SP é até 1o vezes maior em bairros com pior condição social. Portal G1, São Paulo, 29 de abr. de 2020. Disponível em: https:/g1.globo.com/sp/sao-paulo/noticia/2020/o4/29/risco-de-morrer-por-covid-19-em-spe-ate-10-vezes-maior-em-bairros-com-pior-condicao-social.ghtml. Acesso em 29/o4/2020.

\footnotetext{
29 DELEUZE; GUATTARI, Mille plateaux, p. 283. Deleuze e Guattari tem em vista, assim como Virilio, o célebre telegrama 71 de Hitler: Se a guerra está perdida, que pereça a nação. C.f. Idem.

30 SAFATLE, Bem vindo ao Estado suicidário, p. 5.
} 
8 | Ou a vida ou o lucro: a disjuntiva neoliberal e a gestão política da morte em tempos de pandemia

FONTES, V. Solidariedade social ativa $e$ o coronavírus. Disponível em: https://apg.ufsc.br/2020/o3/16/solidariedade-social-ativa-e-o-coronavirus-por-virginiafontes/. Acesso em 25/04/2020.

FONTES, V. Coronavírus e a crise do Capital - Entrevista com Virgínia Fontes. In: Site da Associação dos Docentes da Universidade Federal de Sergipe (ADUFS). Disponível em: https://adufs.org.br/conteudo/1883/coronavirus-e-a-crise-do-capital-entrevista-comvirginia-fontes. Acesso em 26/04/2020.

FOUCAULT, M. Sobre a genealogia da ética: uma revisão do trabalho. In: RABINOW, P.; RABINOW, H. Michel Foucault: uma trajetória filosófica (para além do estruturalismo e da hermenêutica). Rio de Janeiro: Forense Universitária, 1995.

FOUCAULT, M. Em defesa da sociedade: curso no Collège de France (1975-1976). Trad. Maria Ermantina Galvão. São Paulo: Martins Fontes, 2000.

FOUCAULT, M. Naissance de la biopolitque: cours au Collège de France (1978-1979). Paris: Gallimard/Seuil, 2004.

INSTITUTO DE PESQUISAS ECONÔMICAS APLICADAS (IPEA). "Desigualdades

Socioespaciais de Acesso a Oportunidades nas Cidades Brasileiras - 2019”. Disponível em: http://www.ipea.gov.br/portal/index.php?option=com content\&view=article\&id=35268\&Ite mid=444. Acesso em 30/04/2020.

LACAN, J. "Posição do Inconsciente no Congresso de Bonneval - Retomada de 1960 em 1964”. In: Escritos. São Paulo: Perspectiva, 1992.

LATOUR, B. Imaginar los gestos-barrera contra la vuelta a la producción anterior a la crisis. Disponível em: https://ctxt.es/es/20200401/Politica/31797/economia-coronavirus-crisisproduccion-gestos-barrera-empresas-medioambiente-bruno-latour.htm. Acesso em 24/04/2020.

LORENZINI, D. Biopolitics in the Time of Coronavirus. In: Critical Inquiry. Disponível em: https://critinq.wordpress.com/2020/04/02/biopolitics-in-the-time-of-coronavirus/. Acesso em 20/04/2020.

LÖWY, Michael. Barbárie e modernidade no século XX. Disponível em: https://combate.info/barbrie-e-modernidade-no-sulo-Xx/. Acesso em: 29/04/2020.

LÖWY, M. Aviso de incêndio : uma leitura das teses "Sobre o conceito de história". Trad. de Wanda Nogueira Caldeira Brant. São Paulo : Boitempo, 2005.

MBEMBE, A. Necropolítica. Trad. Renata Santini. São Paulo: n-1 Edições, 2018.

NANCY, J-L. Communovirus. In: Libération, 24 mars 2020. Disponível em: https://www.liberation.fr/debats/2020/03/24/communovirus 1782922. Acesso em 27/04/2020.

ROCHA, J. "Biodiversidade é a chave para prever e evitar novas pandemias”. In: Jornal da Ciência, 16/o4/2020. Disponível em: http://www.abc.org.br/2020/o4/16/biodiversidade-echave-para-prever-e-evitar-novas-pandemias/. Acesso em: 30/04/2020.

SAFATLE, V. Bem vindo ao Estado suicidário. São Paulo: N-1, 2020. Disponível em: https://n1edicoes.org/004. Acesso em 29/04/2020.

SANTOS, B. de S. A cruel pedagogia do vírus. Coimbra: Ed. Almedina, 2020. 